\title{
Simulating Sleep Apnea by Exposure to Intermittent Hypoxia Induces Inflammation in the Lung and Liver
}

\author{
Darlan Pase da Rosa, ${ }^{1,2,3}$ Luiz Felipe Forgiarini, ${ }^{2,4}$ Diego Baronio,, 2 \\ Cristiano Andrade Feijó, ${ }^{2,4}$ Dênis Martinez, ${ }^{1,2}$ and Norma Possa Marroni ${ }^{1,2,5}$ \\ ${ }^{1}$ Ciências Médicas, Programa de Pós-Graduação em Medicina, Universidade Federal do Rio Grande do Sul (UFRGS), \\ 90035-903 Porto Alegre, RS, Brazil \\ ${ }^{2}$ Hospital de Clínicas de Porto Alegre (HCPA), Universidade Federal do Rio Grande do Sul, 90035-903 Porto Alegre, RS, Brazil \\ ${ }^{3}$ Faculdade Cenecista de Bento Gonçalves, 95700-973 Bento Gonçalves, RS, Brazil \\ ${ }^{4}$ Programa de Pós-Graduação em Ciências Pneumológicas, Universidade Federal do Rio Grande do Sul (UFRGS), \\ 90035-903 Porto Alegre, RS, Brazil \\ ${ }^{5}$ Universidade Luterana do Brasil, 92425-900 Canoas, RS, Brazil
}

Correspondence should be addressed to Darlan Pase da Rosa, darlanpr@yahoo.com.br

Received 22 September 2012; Revised 15 October 2012; Accepted 28 October 2012

Academic Editor: Fábio Santos Lira

Copyright (C) 2012 Darlan Pase da Rosa et al. This is an open access article distributed under the Creative Commons Attribution License, which permits unrestricted use, distribution, and reproduction in any medium, provided the original work is properly cited.

Sleep apnea is a breathing disorder that results from momentary and cyclic collapse of the upper airway, leading to intermittent hypoxia (IH). IH can lead to the formation of free radicals that increase oxidative stress, and this mechanism may explain the association between central sleep apnea and nonalcoholic steatohepatitis. We assessed the level of inflammation in the lung and liver tissue from animals subjected to intermittent hypoxia and simulated sleep apnea. A total of $12 \mathrm{C} 57 \mathrm{BL} / 6$ mice were divided into two groups and then exposed to IH $(n=6)$ or a simulated $\mathrm{IH}(\mathrm{SIH})(n=6)$ for 35 days. We observed an increase in oxidative damage and other changes to endogenous antioxidant enzymes in mice exposed to IH. Specifically, the expression of multiple transcription factors, including hypoxia inducible factor (HIF- $1 \alpha)$, nuclear factor kappa B (NF- $\kappa \mathrm{B})$, and tumor necrosis factor (TNF- $\alpha$ ), inducible NO synthase (iNOS), vascular endothelial growth factor (VEGF), and cleaved caspase 3 were shown to be increased in the IH group. Overall, we found that exposure to intermittent hypoxia for 35 days by simulating sleep apnea leads to oxidative stress, inflammation, and increased activity of caspase 3 in the liver and lung.

\section{Introduction}

Obstructive sleep apnea (OSA) consists of sleep-disordered breathing. Cyclic episodes result in the momentary closure, partial or complete, of the upper airway at the level of the pharynx. The repeated pauses in breathing can lead to intermittent hypoxia $(\mathrm{IH})$ and increased reactive oxygen species (ROS) [1].

The increase of ROS in OSA is likely due to the repeated oxygen depletion followed by the hyperoxia that develops to restore oxygen pressure $\left(\mathrm{PO}_{2}\right)$. A similar phenomenon is observed in ischemia followed by reperfusion [2-5]. In ischemia/reperfusion, xanthine oxidase generates free radicals in the presence of oxygen, contributing to oxidative stress $[6-8]$.
OSA is associated with chronic liver diseases, such as nonalcoholic steatohepatitis (NASH) [9-16]. Savransky and colleagues demonstrated that IH can act as a "second hit" to liver disease by amplifying the tissue damage induced by a high dose of paracetamol $[17,18]$. The injury mechanism, triggered by OSA, appears to be related to the formation of peroxynitrite, depletion of glutathione, and apoptosis of hepatocytes [18].

In OSA, inflammatory factors, such as nuclear factor kappa B (NF- $\kappa B)$, are activated at a systemic level $[17,19]$. $\mathrm{NF}-\kappa \mathrm{B}$ is a master regulator of the inflammatory process, by inhibiting its inhibitor IKK-b, and its activation leads to the increased expression of tumor necrosis factor (TNF$\alpha$ ), interleukins 1 and 6 , and inducible nitric oxide synthase (iNOS). Alternatively, these factors can be activated by 
hypoxia inducible factor (HIF-1 $\alpha$ ) [20-23], which results in apoptosis [24].

Several studies have shown that OSA is associated with inflammation, NASH, oxidative stress, and apoptosis. This is the first experimental study that evaluated the inflammatory process in the lung and liver with intermittent hypoxia, suggesting that there is a recruitment of inflammatory mediators recognized during ischemia and reperfusion. Here, we investigate the molecular mechanism involved in the lung and liver injury in an animal model of OSA.

\section{Methods}

The experiments were approved and completed according to the Research and Ethics Committee of the Research and Postgraduation at the Hospital de Clínicas de Porto Alegre, Brazil.

A total of 12 C57BL/6 mice ( $8-11$ weeks old) were housed in plastic boxes $(30 \times 19 \times 13 \mathrm{~cm})$ at the Animal Experimentation Unit of the Hospital de Clínicas de Porto Alegre. The mice were kept on a 12-hour light/dark cycle (lights on from $7 \mathrm{AM}$ to $7 \mathrm{PM}$ ) at $22 \pm 4^{\circ} \mathrm{C}$ and given free access to food (Purina-Nutripal, Porto Alegre, RS, Brazil) and water.

The mice were randomly divided into two experimental groups ( $n=6$ per group). The groups consisted of mice exposed to intermittent hypoxia for 35 days (IH group) and mice that underwent a simulation of the $\mathrm{IH}$ procedure $(\mathrm{SIH}$ group).

The mice were placed in intermittent hypoxia chambers 8 hours a day (9 AM to 5 PM) for 5 weeks (Figure 1). The animals were exposed to a gas mixture consisting of $90 \%$ nitrogen and $10 \%$ carbon dioxide for 30 seconds. The gas mixture reduces the oxygen fraction in the chambers by $6 \pm 1 \%$. In sequence, the gas release is then blocked and fans are triggered to restore ambient air for the remaining 30 seconds. The SIH group was housed in a cage and subjected to the same adjacent fan activity as the IH group but no gas was introduced into the cage [25].

After 35 days, the animals were deeply anesthetized with an intraperitoneal injection of ketamine hydrochloride $(100 \mathrm{mg} / \mathrm{kg})$ and xylazine hydrochloride $(50 \mathrm{mg} / \mathrm{kg})$ and the liver and lungs were removed. The organs were immediately frozen in liquid nitrogen and kept at $-80^{\circ} \mathrm{C}$ for subsequent analysis. The animals were euthanized by exsanguination under deep anesthesia $[26,27]$.

The organs were cut and divided for biochemical and protein analyses. For analysis of oxidative stress, $100 \mathrm{mg}$ of tissue was added to $0.9 \mathrm{~mL}$ of buffer $(140 \mathrm{mM} \mathrm{KCl}, 20 \mathrm{mM}$ phosphate, $\mathrm{pH}$ 7.4) and homogenized with a micropestle in microtubes. After centrifugation at $2150.4 \mathrm{~g}$ for 10 minutes in a refrigerated centrifuge $\left(4^{\circ} \mathrm{C}\right)$, the supernatant was discarded and the pellet was stored at $-80^{\circ} \mathrm{C}$ for further analysis. For western blotting, a nuclear extraction protocol was used. Briefly, $100 \mathrm{mg}$ of tissue was added to $0.6 \mathrm{~mL}$ of lysis buffer (25 mM HEPES, 1\% Triton X-100, 2 mM EDTA, $0.1 \mathrm{~mL} \mathrm{NaCl}, 25 \mathrm{mM} \mathrm{NaF}, 1 \mathrm{mM}$ sodium orthovanadate, and a protease inhibitor cocktail) and homogenized with a micropestle in microtubes. After centrifugation at $15,000 \mathrm{~g}$ for 10 minutes at $4^{\circ} \mathrm{C}$, the supernatant was discarded and the pellet was stored at $-80^{\circ} \mathrm{C}$ for further analysis.

\subsection{Oxidative Stress}

2.1.1. Proteins. The protein concentration in the homogenate was measured spectrophotometrically at $595 \mathrm{~nm}$ using the Bradford method. The values are expressed in $\mathrm{mg} / \mathrm{mL}$ [28] and were used in the calculations for the TBARS and antioxidant enzymes.

2.1.2. Assessment of Lipid Peroxidation. The TBARS technique consists of heating the homogenate with thiobarbituric acid to produce a colored product that is subsequently measured at $535 \mathrm{~nm}$ using a spectrophotometer. The change in color is due to the presence of malondialdehyde and other substances produced from lipid peroxidation in the biological material.

Briefly, $0.25 \mathrm{~mL}$ of $10 \%$ trichloroacetic acid (TCA), $0.10 \mathrm{~mL}$ of homogenate, $0.067 \mathrm{~mL}$ of $0.67 \%$ thiobarbituric acid (TBA), and $0.033 \mathrm{~mL}$ of distilled water were added to a tube, stirred, and then heated at $100^{\circ} \mathrm{C}$. After the tubes cooled, $0.20 \mathrm{~mL}$ of n-butyl alcohol was added to extract the pigment. The tubes were then stirred and centrifuged for 10 minutes at $1110 \mathrm{~g}$. A $0.20 \mathrm{~mL}$ aliquot of the supernatant was added to a 96-well plate. The absorbance of the samples was quantified on a spectrophotometer at $535 \mathrm{~nm}$. The TBARS concentration was expressed in nmol per mg protein [29].

2.1.3. Determination of Superoxide Dismutase (SOD). The technique used to measure SOD was based on the level of inhibition caused by the reaction of the enzyme with $\mathrm{O}^{-2}$. We used adrenaline in an alkaline medium to produce adrenochrome and $\mathrm{O}^{-2}[30]$.

In a 96-well plate, we measured SOD activity in the reaction medium (50 mM glycine- $\mathrm{NaOH}, \mathrm{pH} 10$ ) and three samples containing different concentrations of homogenate. After addition of $10.5 \mu \mathrm{L}$ epinephrine $(60 \mathrm{mM}, \mathrm{pH} 2.0)$, the reaction was monitored for $2 \mathrm{~min}$ at $480 \mathrm{~nm}$. The enzymatic activity was expressed in units $\mathrm{SOD} / \mathrm{mg}$ protein.

2.1.4. Determination of Catalase (CAT). Catalase enhances the decomposition of hydrogen peroxide into water and oxygen. The rate of decomposition of hydrogen peroxide is directly proportional to enzyme activity and follows pseudofirst-order kinetics with respect to hydrogen peroxide.

The decrease in absorption at $240 \mathrm{~nm}$ was determined after adding $7 \mu \mathrm{L}$ of $300 \mathrm{mM} \mathrm{H}_{2} \mathrm{O}_{2}$ to the reaction medium (50 $\mathrm{mM}$ phosphate regulator). The catalase concentration was expressed as $\mathrm{pmol} / \mathrm{mg}$ protein [31].

2.2. Western Blots. A total of $50 \mathrm{mg}$ of protein was added to a buffer (60\% glycerol, $2 \mathrm{M}$ Tris, SDS, and 10\% Pyrroline $0.5 \%$ ) and incubated for four minutes at $100^{\circ} \mathrm{C}$. After electrophoresis was performed [32] on a $9-12 \%$ polyacrylamide gel, the protein was transferred to a polyvinylidene difluoride (PVDF) membrane [33]. The membrane was washed with 


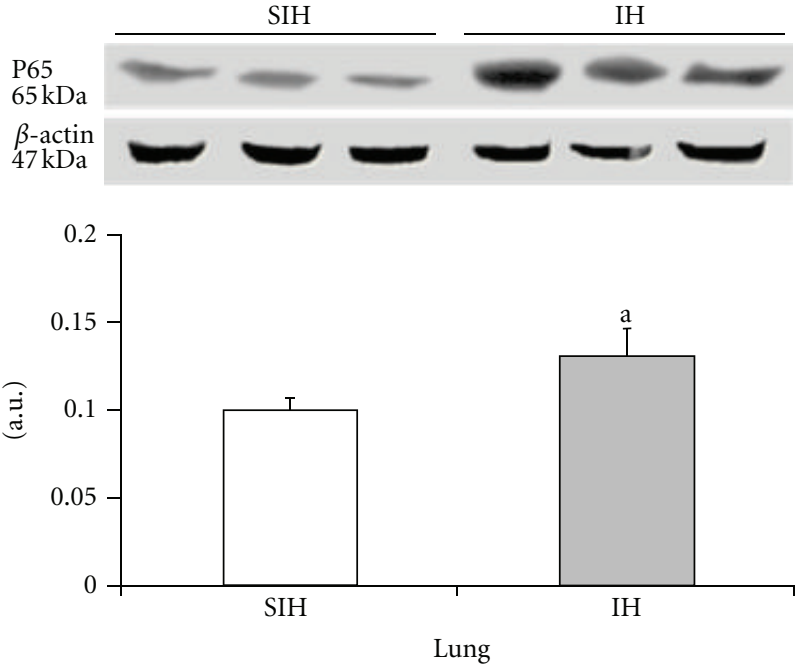

(a)
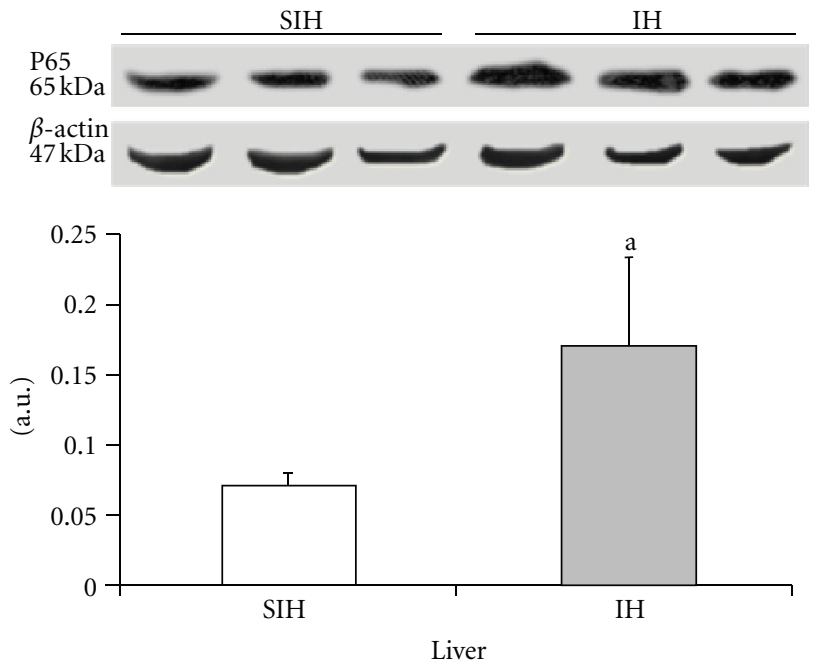

(b)

FIGURE 1: The effect of intermittent hypoxia on the expression of phosphorylated NF- $\kappa \mathrm{B}$ in the liver $((\mathrm{a}), P=0.0247)$ and lung $((\mathrm{b})$, $P=0.0033)$. Results are reported as mean \pm standard error, $n=6$ per group. $P$ value according to Student's $t$-test.

PBS contained $0.5 \%$ Tween 20 and then incubated in a blocking solution $(5 \%$ skim milk powder and $0.5 \%$ Tween 20 in cold PBS) for 30 minutes. After washing, the membrane was incubated overnight at $4^{\circ} \mathrm{C}$ with the primary antibody. Next, the membrane was washed and incubated in the secondary antibody (HRP) for two hours at room temperature. After another wash, the protein was visualized using chemiluminescent detection (Chemiluminescent HRP Substrate), film, and a transiluminator (L-Pix Chemi molecular imagingLoccus Biotechnology). $\beta$-actin was used as a loading control. The results were quantified using LabImage 1D (Loccus Biotechnology) and are expressed as arbitrary units.

2.3. Statistical Analysis. For analyzing the result, the Student's $t$-test was performed using SPSS version 18.0 (Statistical Package for Social Science). The results are represented as the mean \pm standard error of the mean. The statistical significance level was set as $P<0.05$.

\section{Results}

Lipid peroxidation, a marker of oxidative damage, was significantly increased in the lung (14\%) and liver (29\%) of the IH group when compared with the SIH group (Table 1).

The activity of endogenous SOD was significantly lower in lung tissue (56\%) and higher in liver tissue (87\%) from IH animals when compared with the control group (Table 1). The activity of CAT was significantly higher in both organs (32\% in the lung and $184 \%$ in the liver) from the $\mathrm{IH}$ group when compared with the SIH group (Table 1).

The activated (phosphorylated) p65 subunit of NF- $\kappa \mathrm{B}$ was increased by $30 \%$ in the lung and 39\% in the liver of IH mice when compared with SIH mice.

The expression of HIF- $1 \alpha$ and TNF- $\alpha$ was significantly increased in the IH group when compared with the $\mathrm{SIH}$ group (Figures 2 and 3 ). In the lung tissue, HIF- $1 \alpha$ increased by $96 \%$ and TNF- $\alpha$ increased by $38 \%$. In the hepatic tissue, HIF- $1 \alpha$ was increased by $19 \%$ and TNF- $\alpha$ was increased by $48 \%$.

The expression of iNOS and VEGF was significantly higher in the IH group when compared with controls (Figures 4 and 5). There was a 35\% increase in iNOS and a $22 \%$ increase in VEGF in the lung tissue. The liver showed a $79 \%$ increase in iNOS levels and a $71 \%$ increase in VEGF. Cleaved caspase 3 was increased by $237 \%$ in the lung and $182 \%$ in the liver of IH animals when compared to the SIH group (Figure 6).

\section{Discussion}

Animal models that use intermittent hypoxia can help elucidate the mechanism of damage to various systems caused by sleep apnea. Independent of body mass index, the respiratory disturbance index is directly related to the degree of liver damage and is recognized as a risk factor for nonalcoholic fatty liver disease (NAFLD) [10, 34]. It has been proposed that the development of NASH is produced in two phases consisting first of the accumulation of triglyceride, which is attributed to insulin resistance and obesity, and then the presence of inflammation and fibrosis [35], which is correlated with oxidative stress and hepatic lipid peroxidation $[36,37]$.

Our research group has described [38] oxidative damage to membrane lipids measured by TBARS and changes in endogenous antioxidant enzymes in the liver tissue that indicate the role of oxidative stress in our model system. These data are in agreement with the results described in other model systems [38-41]. Oxidative stress occurs through xanthine oxidase by producing the superoxide anion radical $\left(\mathrm{O}_{2}{ }^{-\bullet}\right)$ and hydrogen peroxide $[42,43]$; it is suggested 
TABLE 1: The effect of intermittent hypoxia on hepatic lipid peroxidation as shown by the TBARS assay and liver antioxidant enzyme activity.

\begin{tabular}{|c|c|c|c|c|}
\hline & & $\mathrm{SIH}$ & $\mathrm{IH}$ & $P$ value \\
\hline \multirow{3}{*}{ Liver } & TBARS $_{\text {(nmol/mg prot) }}$ & $2.90 \pm 0.23$ & $3.76 \pm 0.15$ & 0.0389 \\
\hline & $\mathrm{SOD}_{(\mathrm{USOD} / \mathrm{mg} \text { prot})}$ & $3.13 \pm 0.53$ & $5.86 \pm 0.70$ & 0.0118 \\
\hline & $\mathrm{CAT}_{\text {(nmol/mg prot) }}$ & $0.82 \pm 0.17$ & $2.33 \pm 0.09$ & 0.0015 \\
\hline \multirow{3}{*}{ Lung } & TBARS $_{\text {(nmol/mg prot) }}$ & $4.57 \pm 0.10$ & $5.22 \pm 0.10$ & 0.0116 \\
\hline & $\mathrm{SOD}_{\text {(USOD/mg prot) }}$ & $7.27 \pm 0.99$ & $4.64 \pm 0.22$ & 0.0272 \\
\hline & $\mathrm{CAT}_{\text {(nmol/mg prot) }}$ & $2.62 \pm 0.18$ & $3.48 \pm 0.13$ & 0.0042 \\
\hline
\end{tabular}

Results are reported as mean \pm standard error, $n=6$ per group. $P$ value according to Student's $t$-test.

SIH: sham intermittent hypoxia group; IH: intermittent hypoxia.

SOD: superoxide dismutase; CAT: catalase.

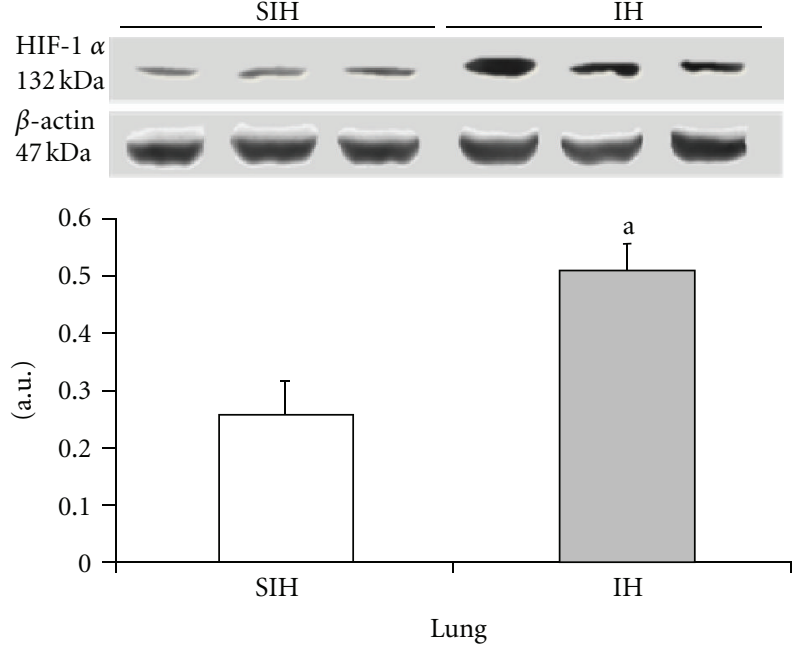

(a)
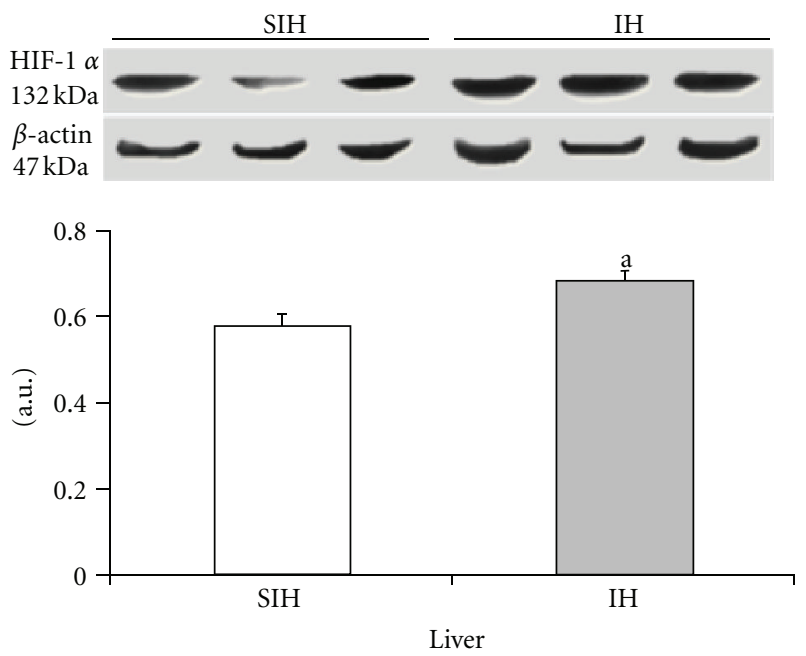

(b)

Figure 2: The effect of intermittent hypoxia on the expression of HIF- $1 \alpha$ in the liver $((\mathrm{a}), P=0.0227)$ and lung $((\mathrm{b}), P=0.0086)$. Results are reported as mean \pm standard error, $n=6$ per group. $P$ value according to Student's $t$-test.

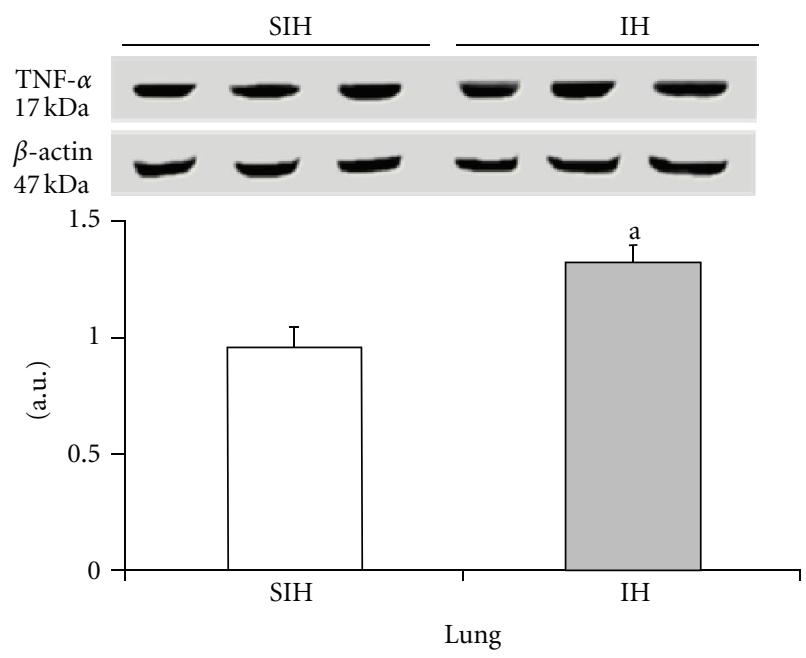

(a)

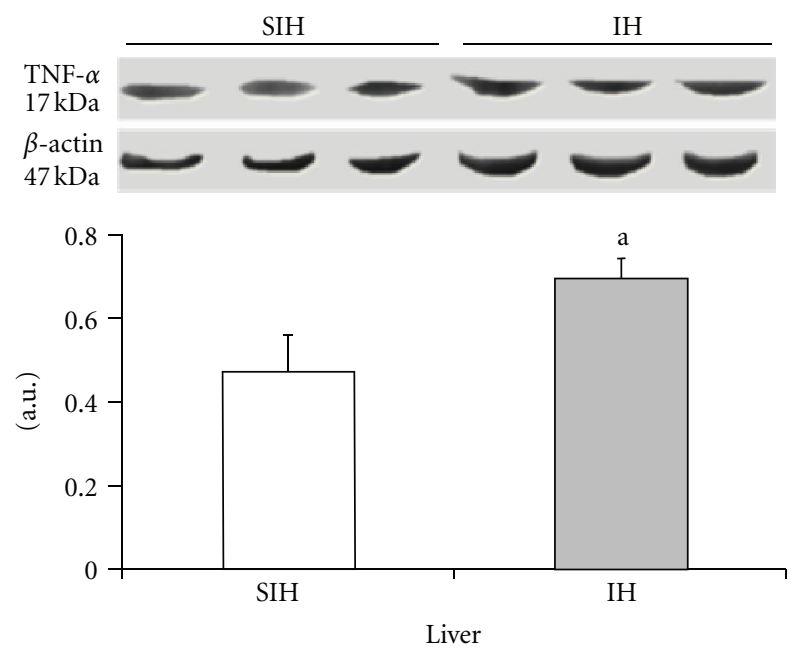

(b)

Figure 3: The effect of intermittent hypoxia on the expression of TNF- $\alpha$ in the liver ((a), $P=0.0382)$ and lung ((b), $P=0.0171)$. Results are reported as mean \pm standard error, $n=6$ per group. $P$ value according to Student's $t$-test. 


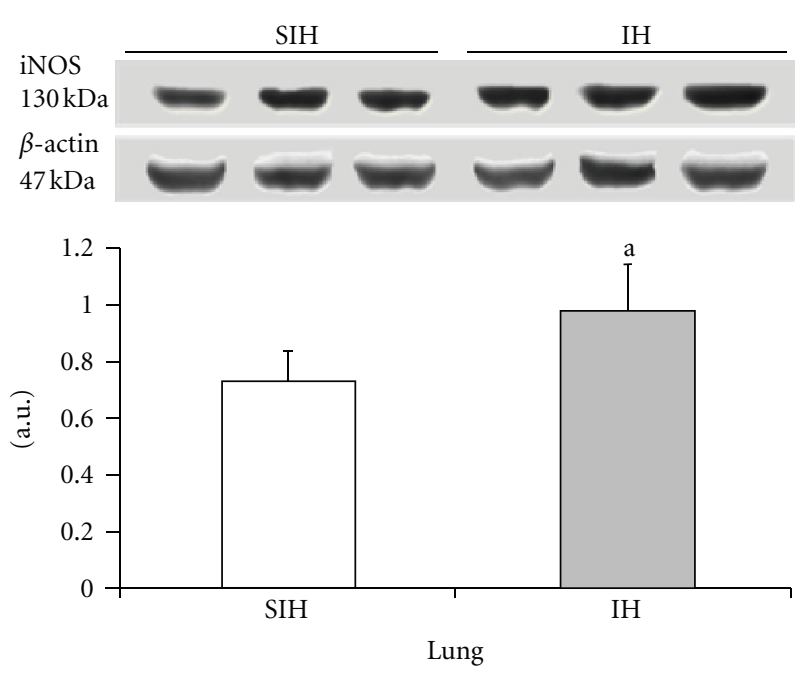

(a)
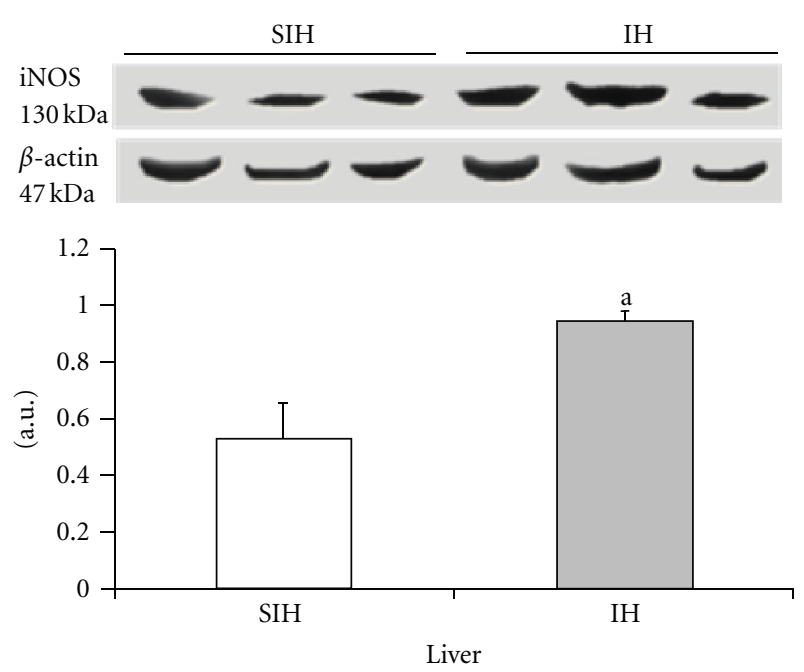

(b)

FIgURE 4: The effect of intermittent hypoxia on the expression of iNOS in the liver ((a), $P=0.0091)$ and lung $((b), P=0.0107)$. Results are reported as mean \pm standard error, $n=6$ per group. $P$ value according to Student's $t$-test.
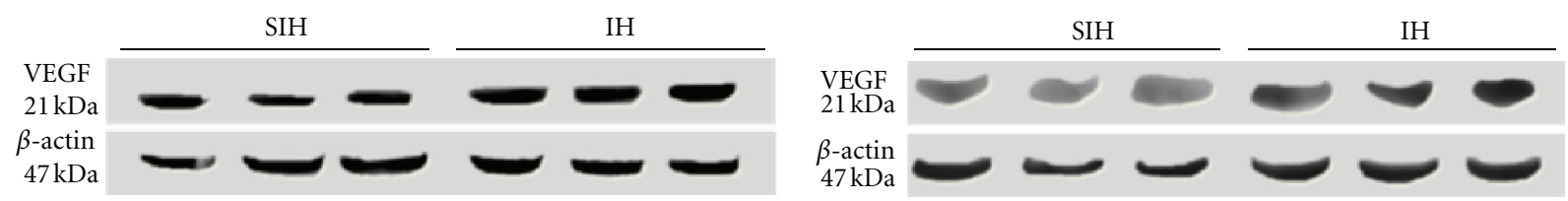

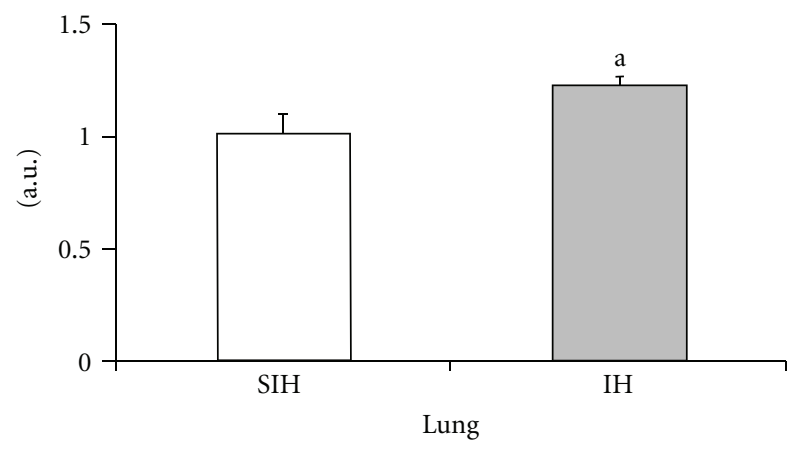

(a)

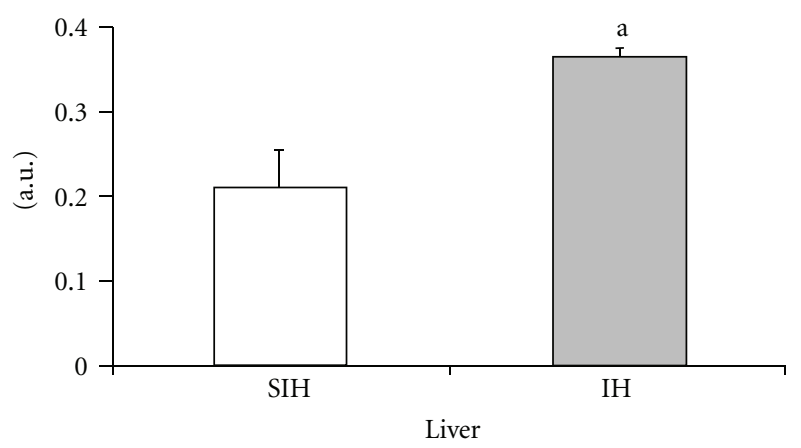

(b)

FIgURE 5: The effect of intermittent hypoxia on the expression of VEGF in the liver ((a), $P=0.0062)$ and lung $((\mathrm{b}), P=0.0184)$. Results are reported as mean \pm standard error, $n=6$ per group. $P$ value according to Student's $t$-test.

that the $\mathrm{O}_{2}{ }^{-\bullet}$ and $\mathrm{H}_{2} \mathrm{O}_{2}$, formed by the activity of xanthine oxidase, act independently on the activity of SOD and CAT [44]. Nitrosative stress includes the formation of nitric oxide (NO) that binds $\mathrm{O}_{2}{ }^{-}$to form the radical peroxynitrite $[38,42,45,46]$.

HIF- $1 \alpha$ regulates the concentration of oxygen, and it can be the initiator of inflammation in intermittent hypoxia $[47,48]$ or stimulated by oxidative stress [49]. This protein is correlated with chronic alcohol use and the presence of NAFLD [50]. HIF- $1 \alpha$ also stimulates macrophages, increases the production of VEGF and iNOS [51, 52], reduces apoptosis [24, 53], and stimulates cell proliferation [54].
It is suggested that inflammatory activity is dependent on NF- $\kappa \mathrm{B}$ [55], indicating that NF- $\kappa \mathrm{B}$ can regulate HIF$1 \alpha$ transcription [56]. Although indirect, inhibition of IKK experimentally prevents the activation of NF- $\kappa \mathrm{B}$ and was found to prevent the development of steatosis and NASH [57]. In the present study, we observed an increase in the expression of HIF- $1 \alpha$ in the liver and the lung of mice exposed to hypoxia.

The stimulation of TNF- $\alpha$ leads to phosphorylation of $\mathrm{I} \kappa \mathrm{B}$, which results in activation of NF- $\kappa \mathrm{B}$. Activation of $\mathrm{NF}-\kappa \mathrm{B}$ causes it to translocate to the nucleus and promote the transcription of numerous proinflammatory genes [58]. 

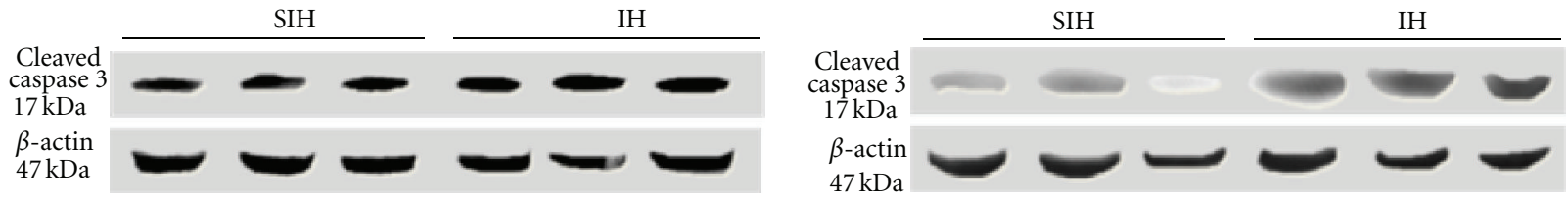

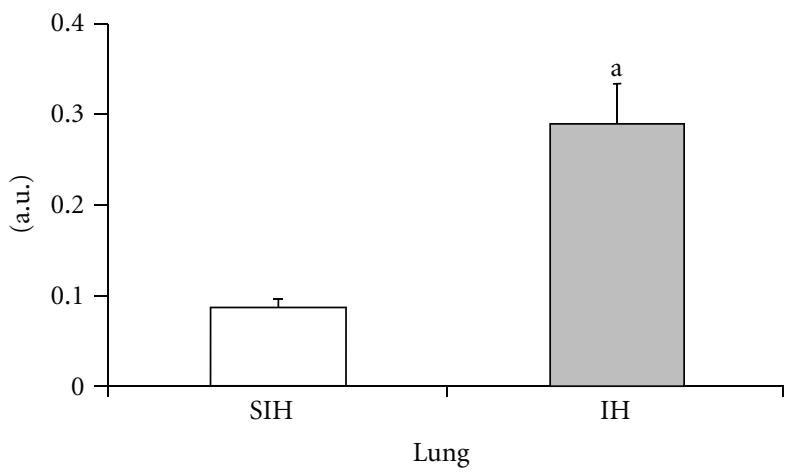

(a)

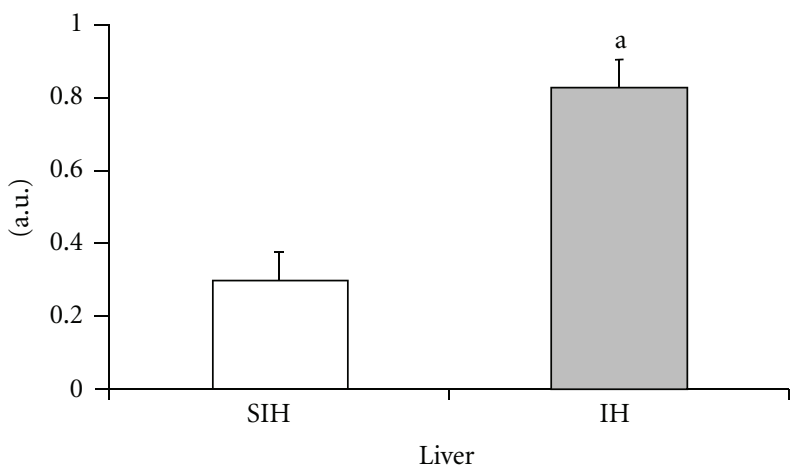

(b)

Figure 6: The effect of intermittent hypoxia on the expression of cleaved caspase 3 in the liver ((a), $P=0.0022)$ and lung ((b), $P=0.0003)$. Results are reported as mean \pm standard error, $n=6$ per group. $P$ value according to Student's $t$-test.

Here, we showed that TNF- $\alpha$ and NF- $\kappa \mathrm{B}$ were increased in animals exposed to intermittent hypoxia.

VEGF is essential for the initiation of angiogenesis, and it has a strong effect on vascular elements in response to hypoxia $[59,60]$. In this study, we found increased expression of VEGF in both organs when mice were subjected to intermittent hypoxia.

In our previous work, we found that there is an increase in nitric oxide metabolites (NO) after exposure to intermittent hypoxia [38]. In the present study, we evaluated an enzyme responsible for NO production, iNOS, and found that the levels of this enzyme were increased in the lung and liver of animals exposed to hypoxia.

Apoptosis in all cells is regulated by caspases. After cleavage, caspases become active and initiate pathways that lead to apoptosis [61]. We found that cleaved caspase 3 expression is increased in the liver and lung of the IH group, demonstrating that there was activation of this apoptotic cascade.

Thus, the data suggest that intermittent hypoxia leads to liver and lung damage that can result from a cascade of signals initiated by oxidative stress, inflammation, and apoptosis.

\section{Conclusion}

In mice, the cyclic oxygen deprivation observed in sleep apnea induces oxidative stress and activation of HIF- $1 \alpha$, which stimulates a cascade of inflammatory signaling, nitric oxide generation, angiogenesis, and apoptosis in the lung and liver.

\section{Acknowledgments}

This paper was supported by the Research Incentive Fund of the Hospital de Clínicas de Porto Alegre (HCPA-FIPE), the Coordination of Improvement of Higher Education Personnel (CAPES), the National Council of Scientific and Technological Development (CNPq), and the Lutheran University of Brazil (ULBRA).

\section{References}

[1] J. A. Dempsey, S. C. Veasey, B. J. Morgan, and C. P. O'Donnell, "Pathophysiology of sleep apnea," Physiological Reviews, vol. 90, no. 1, pp. 47-112, 2010.

[2] L. Lavie, "Obstructive sleep apnoea syndrome-an oxidative stress disorder," Sleep Medicine Reviews, vol. 7, no. 1, pp. 35$51,2003$.

[3] L. Lavie, "Sleep-disordered breathing and cerebrovascular disease: a mechanistic approach," Neurologic Clinics, vol. 23, no. 4, pp. 1059-1075, 2005.

[4] Y. J. Suzuki, V. Jain, A. M. Park, and R. M. Day, "Oxidative stress and oxidant signaling in obstructive sleep apnea and associated cardiovascular diseases," Free Radical Biology and Medicine, vol. 40, no. 10, pp. 1683-1692, 2006.

[5] L. Lavie, "Oxidative stress-A unifying paradigm in obstructive sleep apnea and comorbidities," Progress in Cardiovascular Diseases, vol. 51, no. 4, pp. 303-312, 2009.

[6] T. K. Aalto and K. O. Raivio, "Nucleotide depletion due to reactive oxygen metabolites in endothelial cells: effects of antioxidants and 3-aminobenzamide," Pediatric Research, vol. 34, no. 5, pp. 572-576, 1993.

[7] C. Szabó, B. Zingarelli, and A. L. Salzman, "Role of poly-ADP ribosyltransferase activation in the vascular contractile and energetic failure elicited by exogenous and endogenous nitric oxide and peroxynitrite," Circulation Research, vol. 78, no. 6, pp. 1051-1063, 1996.

[8] J. Zhang, V. L. Dawson, T. M. Dawson, and S. H. Snyder, "Nitric oxide activation of poly(ADP-ribose) synthetase in neurotoxicity," Science, vol. 263, no. 5147, pp. 687-689, 1994.

[9] H. Singh, R. Pollock, J. Uhanova, M. Kryger, K. Hawkins, and G. Y. Minuk, "Symptoms of obstructive sleep apnea in patients 
with nonalcoholic fatty liver disease," Digestive Diseases and Sciences, vol. 50, no. 12, pp. 2338-2343, 2005.

[10] F. Tanné, F. Gagnadoux, O. Chazouillères et al., "Chronic liver injury during obstructive sleep apnea," Hepatology, vol. 41, no. 6, pp. 1290-1296, 2005.

[11] K. Tatsumi and T. Saibara, "Effects of obstructive sleep apnea syndrome on hepatic steatosis and nonalcoholic steatohepatitis," Hepatology Research, vol. 33, no. 2, pp. 100-104, 2005.

[12] P. Jouët, J. M. Sabaté, D. Maillard et al., "Relationship between obstructive sleep apnea and liver abnormalities in morbidly obese patients: a prospective study," Obesity Surgery, vol. 17, no. 4, pp. 478-485, 2007.

[13] E. R. Kallwitz, J. Herdegen, J. Madura, S. Jakate, and S. J. Cotler, "Liver enzymes and histology in obese patients with obstructive sleep apnea," Journal of Clinical Gastroenterology, vol. 41, no. 10, pp. 918-921, 2007.

[14] D. Zamora-Valdés and N. Méndez-Sánchez, "Experimental evidence of obstructive sleep apnea syndrome as a second hit accomplice in nonalcoholic steatohepatitis pathogenesis," Annals of Hepatology, vol. 6, no. 4, pp. 281-283, 2007.

[15] L. Kheirandish-Gozal, O. Sans Capdevila, E. Kheirandish, and D. Gozal, "Elevated serum aminotransferase levels in children at risk for obstructive sleep apnea," Chest, vol. 133, no. 1, pp. 92-99, 2008.

[16] D. Norman, W. A. Bardwell, F. Arosemena et al., "Serum aminotransferase levels are associated with markers of hypoxia in patients with obstructive sleep apnea," Sleep, vol. 31, no. 1, pp. 121-126, 2008.

[17] V. Savransky, A. Nanayakkara, A. Vivero et al., "Chronic intermittent hypoxia predisposes to liver injury," Hepatology, vol. 45, no. 4, pp. 1007-1013, 2007.

[18] V. Savransky, C. Reinke, J. Jun et al., "Chronic intermittent hypoxia and acetaminophen induce synergistic liver injury in mice: experimental physiology_-research paper," Experimental Physiology, vol. 94, no. 2, pp. 228-239, 2009.

[19] S. Ryan, C. T. Taylor, and W. T. McNicholas, "Systemic inflammation: a key factor in the pathogenesis of cardiovascular complications in obstructive sleep apnoea syndrome?" Thorax, vol. 64, no. 7, pp. 631-636, 2009.

[20] A. K. Htoo, H. Greenberg, S. Tongia et al., "Activation of nuclear factor $\kappa \mathrm{B}$ in obstructive sleep apnea: a pathway leading to systemic inflammation," Sleep and Breathing, vol. 10, no. 1, pp. 43-50, 2006.

[21] H. Greenberg, X. Ye, D. Wilson, A. K. Htoo, T. Hendersen, and S. F. Liu, "Chronic intermittent hypoxia activates nuclear factor- $\kappa \mathrm{B}$ in cardiovascular tissues in vivo," Biochemical and Biophysical Research Communications, vol. 343, no. 2, pp. 591596, 2006.

[22] C. Selmi, N. Montano, R. Furlan, C. L. Keen, and M. E. Gershwin, "Inflammation and oxidative stress in obstructive sleep apnea syndrome," Experimental Biology and Medicine, vol. 232, no. 11, pp. 1409-1413, 2007.

[23] M. Yamauchi, S. Tamaki, K. Tomoda et al., "Evidence for activation of nuclear factor kappaB in obstructive sleep apnea," Sleep and Breathing, vol. 10, no. 4, pp. 189-193, 2006.

[24] P. Carmeliet, Y. Dor, J. M. Herbert et al., "Role of HIF- $1 \alpha$ in hypoxia-mediated apoptosis, cell proliferation and tumour angiogenesis," Nature, vol. 395, no. 6701, pp. 485-490, 1998.

[25] D. Martinez, C. Z. Fiori, D. Baronio et al., "Brown adipose tissue: is it affected by intermittent hypoxia?" Lipids in Health and Disease, vol. 9, article no. 121, 2010.

[26] [Anon], "AVMA updates its euthanasia guidelines," Veterinary Record, vol. 161, no. 15, pp. 502-502, 2007.
[27] [Anon], "AVMA releases updated euthanasia guidelines," Journal of the American Veterinary Medical Association, vol. 231, no. 6, pp. 827-827, 2007.

[28] M. M. Bradford, "A rapid and sensitive method for the quantitation of microgram quantities of protein utilizing the principle of protein dye binding," Analytical Biochemistry, vol. 72, no. 1-2, pp. 248-254, 1976.

[29] J. A. Buege and S. D. Aust, "Microsomal lipid peroxidation," Methods in Enzymology, vol. 52, pp. 302-310, 1978.

[30] H. P. Misra and I. Fridovich, "The role of superoxide anion in the autoxidation of epinephrine and a simple assay for superoxide dismutase," Journal of Biological Chemistry, vol. 247, no. 10, pp. 3170-3175, 1972.

[31] H. Aebi, "Catalase in vitro," Methods in Enzymology, vol. 105, pp. 121-126, 1984.

[32] U. K. Laemmli, "Cleavage of structural proteins during the assembly of the head of bacteriophage T4," Nature, vol. 227, no. 5259, pp. 680-685, 1970.

[33] H. Towbin, T. Staehelin, and J. Gordon, "Electrophoretic transfer of proteins from polyacrylamide gels to nitrocellulose sheets: procedure and some applications," Proceedings of the National Academy of Sciences of the United States of America, vol. 76, no. 9, pp. 4350-4354, 1979.

[34] I. Shpirer, L. Copel, E. Broide, and A. Elizur, "Continuous positive airway pressure improves sleep apnea associated fatty liver," Lung, vol. 188, no. 4, pp. 301-307, 2010.

[35] C. P. Day and O. F. W. James, "Steatohepatitis: a tale of two "Hits"?" Gastroenterology, vol. 114, no. 4, pp. 842-845, 1998.

[36] S. Seki, T. Kitada, and H. Sakaguchi, "Clinicopathological significance of oxidative cellular damage in non-alcoholic fatty liver diseases," Hepatology Research, vol. 33, no. 2, pp. 132-134, 2005.

[37] J. George, N. Pera, N. Phung, I. Leclercq, J. Y. Hou, and G. Farrell, "Lipid peroxidation, stellate cell activation and hepatic fibrogenesis in a rat model of chronic steatohepatitis," Journal of Hepatology, vol. 39, no. 5, pp. 756-764, 2003.

[38] D. P. Rosa, D. Martinez, J. N. Picada, J. G. Semedo, and N. P. Marroni, "Hepatic oxidative stress in an animal model of sleep apnoea: effects of different duration of exposure," Comparative Hepatology, vol. 10, article 1, 2011.

[39] A. M. Park and Y. J. Suzuki, "Effects of intermittent hypoxia on oxidative stress-induced myocardial damage in mice," Journal of Applied Physiology, vol. 102, no. 5, pp. 1806-1814, 2007.

[40] A. Dutta, K. Ray, V. K. Singh, P. Vats, S. N. Singh, and S. B. Singh, "L-carnitine supplementation attenuates intermittent hypoxia-induced oxidative stress and delays muscle fatigue in rats," Experimental Physiology, vol. 93, no. 10, pp. 1139-1146, 2008.

[41] S. Bertuglia and R. J. Reiter, "Melatonin reduces microvascular damage and insulin resistance in hamsters due to chronic intermittent hypoxia," Journal of Pineal Research, vol. 46, no. 3, pp. 307-313, 2009.

[42] L. Lavie, A. Hefetz, R. Luboshitzky, and P. Lavie, "Plasma levels of nitric oxide and L-arginine in sleep apnea patients: effects of nCPAP treatment," Journal of Molecular Neuroscience, vol. 21, no. 1, pp. 57-63, 2003.

[43] H. Y. Sohn, F. Krotz, T. Gloe et al., "Differential regulation of xanthine and $\mathrm{NAD}(\mathrm{P}) \mathrm{H}$ oxidase by hypoxia in human umbilical vein endothelial cells. Role of nitric oxide and adenosine," Cardiovascular Research, vol. 58, no. 3, pp. 638646, 2003.

[44] G. Cairo, E. Castrusini, G. Minotti, and A. Bernelli-Zazzera, "Superoxide and hydrogen peroxide-dependent inhibition of 
iron regulatory protein activity: a protective stratagem against oxidative injury," The FASEB Journal, vol. 10, no. 11, pp. 13261335, 1996.

[45] W. Jordan, S. Cohrs, D. Degner et al., "Evaluation of oxidative stress measurements in obstructive sleep apnea syndrome," Journal of Neural Transmission, vol. 113, no. 2, pp. 239-254, 2006.

[46] S. A. Phillips, E. B. Olson, J. H. Lombard, and B. J. Morgan, "Chronic intermittent hypoxia alters NE reactivity and mechanics of skeletal muscle resistance arteries," Journal of Applied Physiology, vol. 100, no. 4, pp. 1117-1123, 2006.

[47] D. R. Mole, C. Blancher, R. R. Copley et al., "Genome-wide association of hypoxia-inducible factor (HIF)- $1 \alpha$ and HIF- $2 \alpha$ DNA binding with expression profiling of hypoxia-inducible transcripts," Journal of Biological Chemistry, vol. 284, no. 25, pp. 16767-16775, 2009.

[48] G. L. Semenza, "Regulation of oxygen homeostasis by hypoxia-Inducible factor 1," Physiology, vol. 24, no. 2, pp. 97106, 2009.

[49] G. Yuan, S. A. Khan, W. Luo et al., "Hypoxia-inducible factor 1 mediates increased expression of NADPH oxidase2 in response to intermittent hypoxia," Journal of Cellular Physiology, vol. 226, no. 11, pp. 2925-2933, 2011.

[50] B. Nath, I. Levin, T. Csak et al., "Hepatocyte-specific hypoxiainducible factor- $1 \alpha$ is a determinant of lipid accumulation and liver injury in alcohol-induced steatosis in mice," Hepatology, vol. 53, no. 5, pp. 1526-1537, 2011.

[51] C. C. Blouin, E. L. Pagé, G. M. Soucy, and D. E. Richard, "Hypoxic gene activation by lipopolysaccharide in macrophages: implication of hypoxia-inducible factor $1 \alpha$," Blood, vol. 103, no. 3, pp. 1124-1130, 2004.

[52] C. Peyssonnaux, P. Cejudo-Martin, A. Doedens, A. S. Zinkernagel, R. S. Johnson, and V. Nizet, "Cutting edge: essential role of hypoxia inducible factor- $1 \alpha$ in development of lipopolysaccharide-induced sepsis," Journal of Immunology, vol. 178, no. 12, pp. 7516-7519, 2007.

[53] W. Moritz, F. Meier, D. M. Stroka et al., "Apoptosis in hypoxic human pancreatic islets correlates with HIF-1alpha expression," The FASEB Journal, vol. 16, no. 7, pp. 745-747, 2002.

[54] N. Akakura, M. Kobayashi, I. Horiuchi et al., "Constitutive expression of hypoxia-inducible factor-l $\alpha$ renders pancreatic cancer cells resistant to apoptosis induced by hypoxia and nutrient deprivation," Cancer Research, vol. 61, no. 17, pp. 6548-6554, 2001.

[55] P. van Uden, N. S. Kenneth, and S. Rocha, "Regulation of hypoxia-inducible factor- $1 \alpha$ a by NF- $\kappa$ B," Biochemical Journal, vol. 412, no. 3, pp. 477-484, 2008.

[56] J. Rius, M. Guma, C. Schachtrup et al., "NF- $\kappa$ B links innate immunity to the hypoxic response through transcriptional regulation of HIF-1 $\alpha$," Nature, vol. 453, no. 7196, pp. 807-811, 2008.

[57] N. Beraza, Y. Malato, S. Vander Borght et al., "Pharmacological IKK2 inhibition blocks liver steatosis and initiation of nonalcoholic steatohepatitis," Gut, vol. 57, no. 5, pp. 655-663, 2008.

[58] H. L. Pahl, "Activators and target genes of Rel/NF- $\kappa \mathrm{B}$ transcription factors," Oncogene, vol. 18, no. 49, pp. 6853-6866, 1999.

[59] N. Ferrara, "Vascular endothelial growth factor: basic science and clinical progress," Endocrine Reviews, vol. 25, no. 4, pp. 581-611, 2004.
[60] E. Minet, G. Michel, J. Remacle, and C. Michiels, "Role of HIF-1 as a transcription factor involved in embryonic development, cancer progression and apoptosis," International Journal of Molecular Medicine, vol. 5, no. 3, pp. 253-259, 2000.

[61] A. E. Greijer and E. Van Der Wall, "The role of hypoxia inducible factor 1 (HIF-1) in hypoxia induced apoptosis," Journal of Clinical Pathology, vol. 57, no. 10, pp. 1009-1014, 2004. 


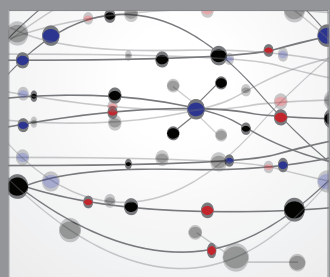

The Scientific World Journal
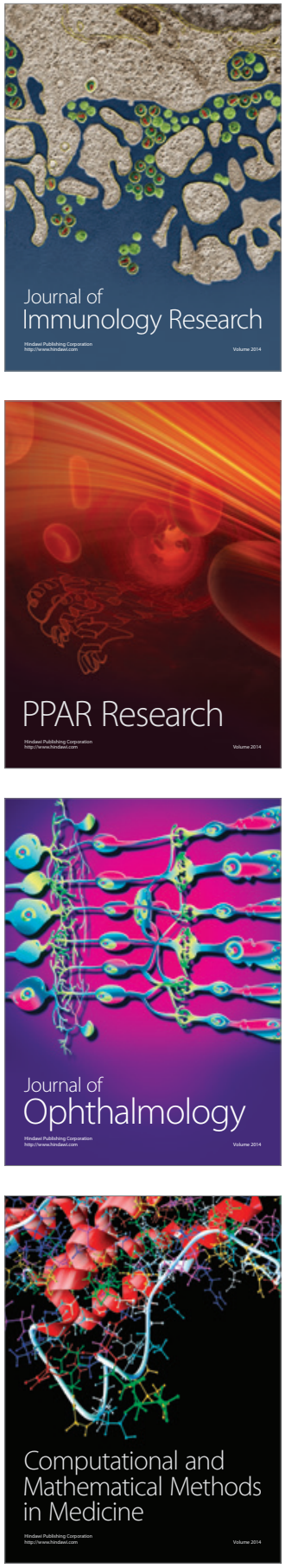

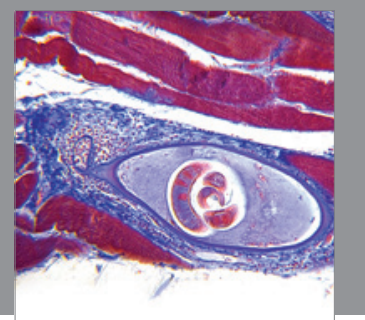

Gastroenterology

Research and Practice
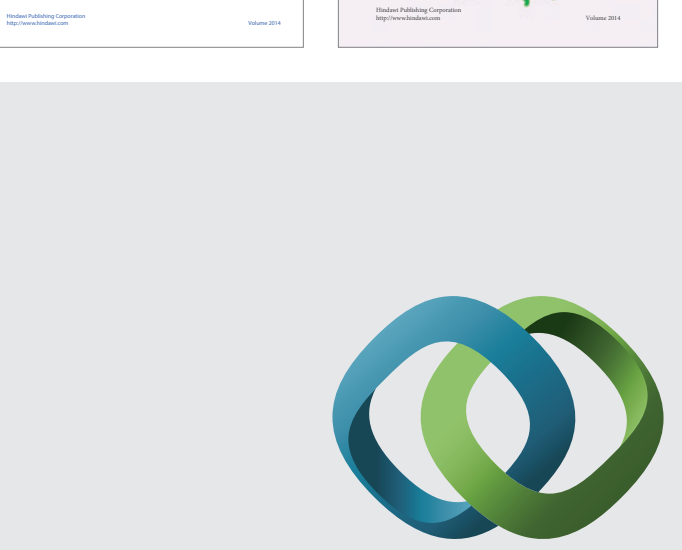

\section{Hindawi}

Submit your manuscripts at

http://www.hindawi.com
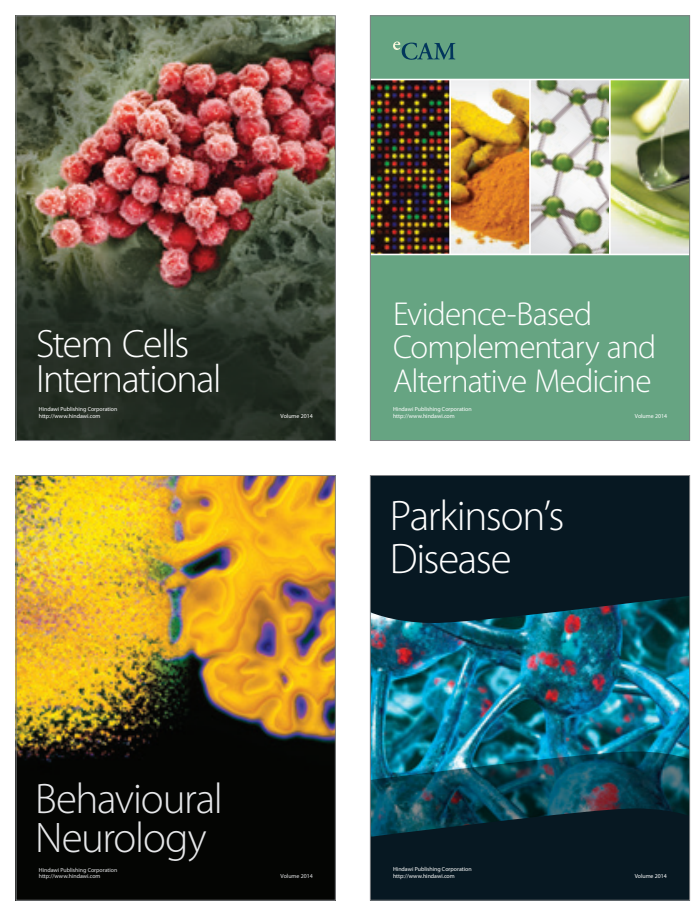

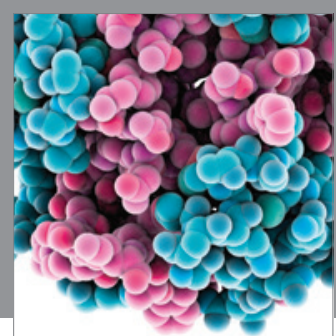

Journal of
Diabetes Research

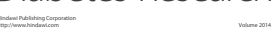

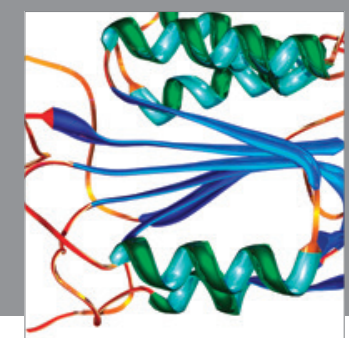

Disease Markers
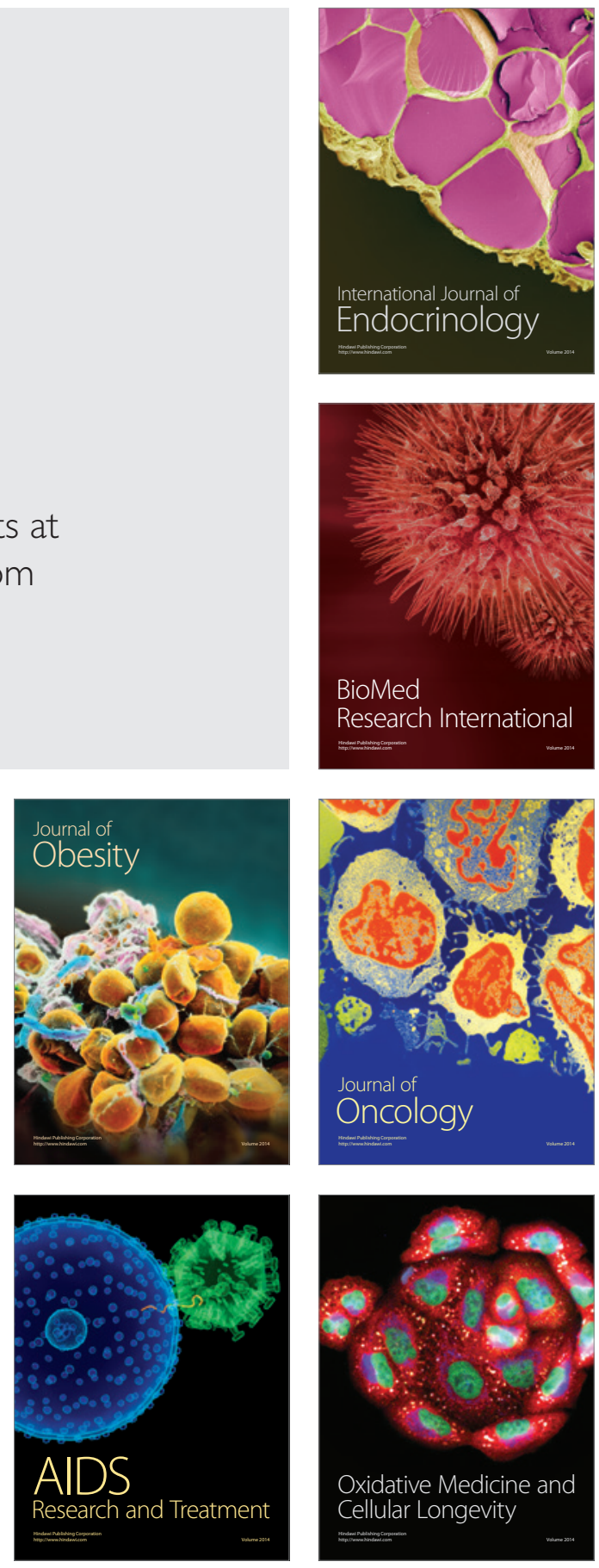